SANDIA REPORT SAND81-2584 • Unlimited Release • UC-70

Printed June 1982

\title{
Permeability Change Near Instrumentation Holes in Jointed Rock: Implications for the Tuff Radionuclide Migration Field Experiment
}

Robert P. Rechard, Karl W. Schuler

Prepared by

Sandia National Laboratories

Albuquerque, New Mexico 87185 and Livermore, California 94550

for the United States Department of Energy

under Contract DE-AC04-76DP00789

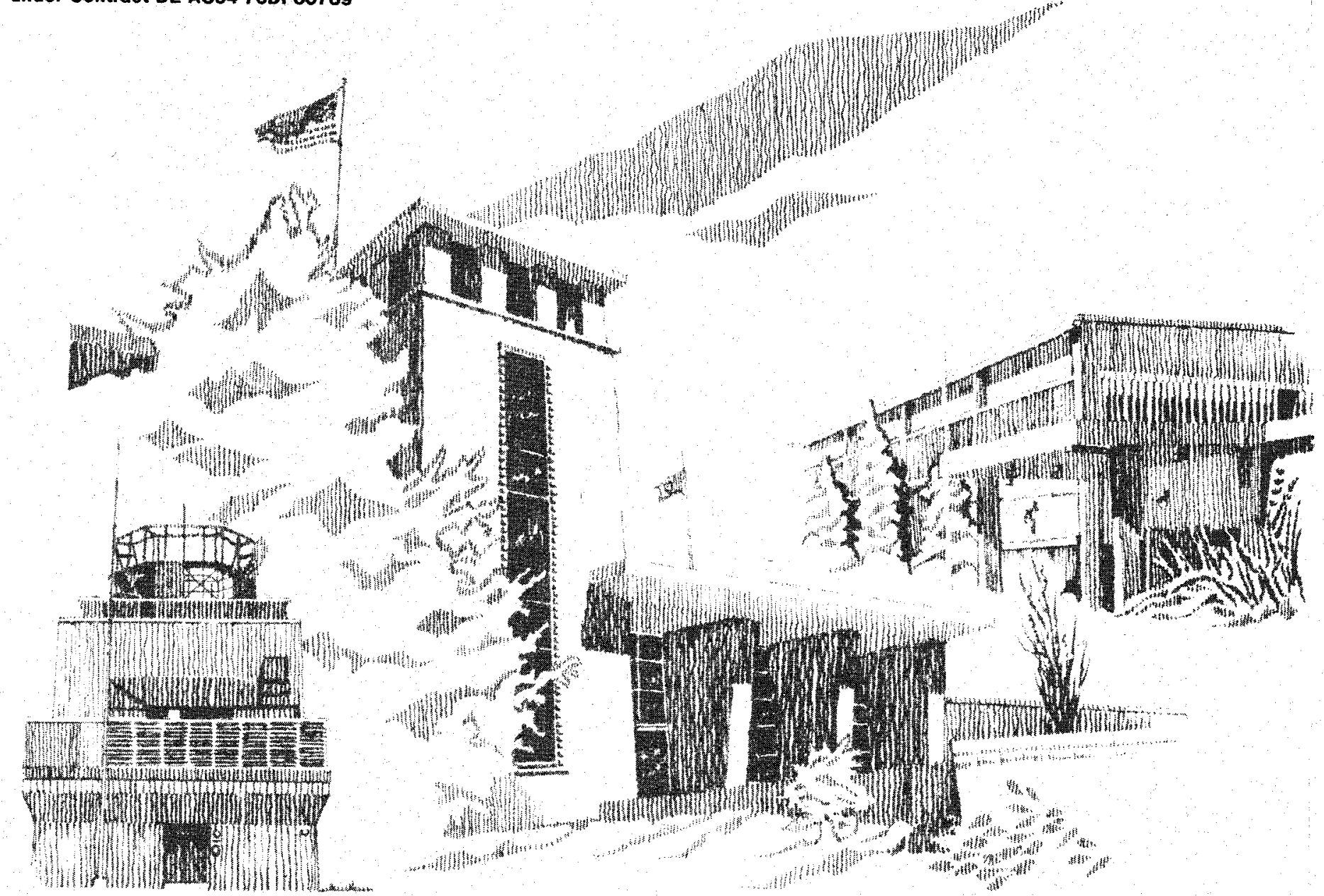


Issued by Sandia National Laboratories, operated for the United States Department of Rnergy by Sandia Corporation.

NOHCD. This teport was prepared as an account of work gponsored by an agency of the United Stotes Covernment. Neither the United Btates Conernment nor any brency thereof, nor any of their employees, nor any of thet

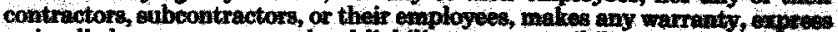

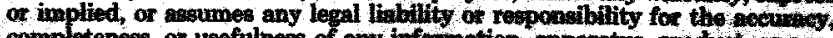

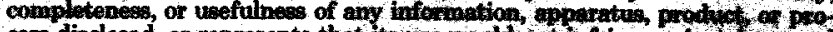

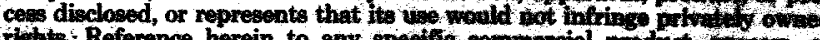

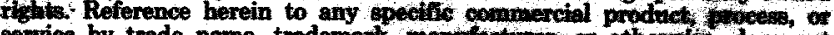

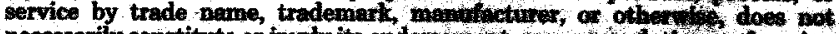

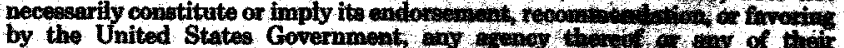

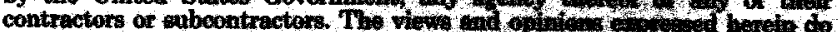

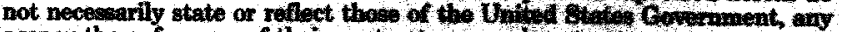

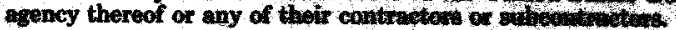

Printed in the United States of Americe Avaliable from

National Technical Information Service

U.S. Department of Commerce

5285 Port Royal Road

Springfield, VA 22161

NTIS price codes

Printed copy: A02

Microfiche copy: A01 
$U C-70$

SAND 81-2584

\author{
Permeability Change Near Instrumentation Holes \\ In Jointed Rock: \\ Implications for the Tuff Radionuclide \\ Migration Field Experiment
}

\author{
R. P. Rechard \\ K. W. Schuler \\ Applied Mechanics Division 5522 \\ Sandia National Laboratories \\ Albuquerque, New Mexico 87185
}

\begin{abstract}
In order to assess in situ joint permeability near waste repositories, it has been proposed that instrumentation holes with axes parallel to the joint plane be drilled. However, the drill holes alter the normal stress across the joint. The resultant stress concentration decreases the joint aperture and can significantly affect the joint permeability. Different intersections of the hole axis relative to the joint plane were examined utilizing a plane-strain, elastic analysis. It was found that a tangential joint intersection minimized the normal stress change. Stress along the joint increased by only 10-15 percent and the permeability-aperture product decreased to 65-70 percent of its original value.
\end{abstract}




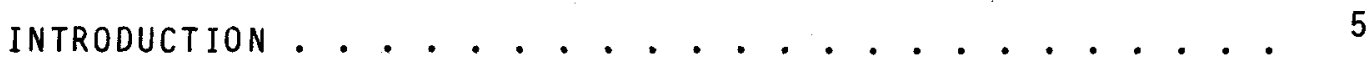

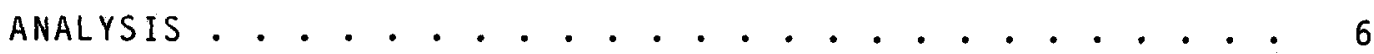

stresses................ 9

Permeability................ 11

CONCLUSIONS AND RECOMMENDATIONS. ......... 17

REFERENCES ......................... 19

\section{ILLUSTRATIONS}

Figure

1. Definition of Terms: a) Cylindrical Drill Hole in Solid Mass Under Plane Strain, Isothermal, and Elastic Conditions; b) Drill Hole - Fracture Configuration. . . . . . . . . . . . . .

2. Normal Stress Concentration Along a Joint for Three Horizontal-Vertical Stress Ratios,
$P_{x}=n P_{y}$
a) $n=0.5$
b) $n=1.0$
c) $n=2.0 .$.

3. Shear Stress Changes Along a Joint for Three Horizontal-Vertical Stress Ratios, $P_{x}=n P_{y} \quad$ a) $n=0.5 \quad$ b) $n=1.0$

c) $n=2.0 .$.

4. Postulated Permeability Changes Using Cubic

Logarithmic Law, $P_{x,}=n P_{y}$ a) $n=0.5$

b) $n=1.0$

c) $n=2.0$. 


\section{IN TRODUCTION}

Nuclear waste disposal requires the establishment of numerous barriers between the waste and man's environment such that a large safety margin exists with very low probability of complete barrier failure. Deep burial provides a natural geologic barrier. However, the prediction of the nuclide retardation provided by the geologic barrier requires knowledge of the hydrological and chemical properties of the formation.

Volcanic tuff at the Nevada Test Site (NTS) is being evaluated as a potential waste disposal medium. A field nuclide migration experiment has been proposed in order to evaluate hydrologic properties, examine chemical reactions with tuff, and verify current numerical transport models (Erdal, et al, 1981). Because of the potential for groundwater to transport radionuclides in the jointed tuff, the focus of the project has been on understanding flow in a single fracture.

The hydrology of fractured rock is in the early stages of development; hence, there are few large-scale laboratory or field experiments to emulate. The nuclide experiment as presently conceived, involves drilling instrumentation holes with axes parallel to the joint plane. However, the drill holes alter the normal stress at the joint which changes the joint aperture and significantly affects the joint permeability. Hence, comparisons of field results with numerical models are made more difficult.

A dominating feature of the flow behavior is the fracture permeability. This report attempts to evaluate effects of the present experiment configuration on the fracture* permeability.

\footnotetext{
*Rock discontinuities or failure surfaces are often referred to as: 1) faults when lateral movement has occurred along the failure plane, 2) joints when subparallel-sets of failure surfaces exist, and 3 ) fissures for discontinuites which are small in extent and aperture. The term fracture is usually a more general description of a failure surface. However, for this report fracture and joint are used interchangeably to describe a single failure surface.
} 
ANALYSIS

Stresses

In rock stressed below one-half its ultimate compressive strength and in which joints are tight and widely spaced, it is usually acceptable to consider the rock as a continuous, linearly elastic material (Goodman, 1980). By also assuming the rock is homogeneous, isotropic, and isothermal, the stress distribution around a cylindrical hole is described by the Kirsch solution (Poulos and Davis, 1974). (Terms are defined in Figure 1.)

$$
\begin{aligned}
& \frac{\sigma_{r}}{P_{y}}=\frac{1+n}{2}\left[1-\left(\frac{a}{r}\right)^{2}\right]+\frac{1-n}{2}\left[1-4\left(\frac{a}{r}\right)^{2}+3\left(\frac{a}{r}\right)^{4}\right] \cos 2 \theta \\
& \frac{\sigma_{\theta}}{P_{y}}=\frac{1+n}{2}\left[1+\left(\frac{a}{r}\right)^{2}\right]-\frac{1-n}{2}\left[1+3\left(\frac{a}{r}\right)^{4}\right] \cos 2 \theta \\
& \frac{{ }^{T} r \theta}{P_{y}}=-\frac{1-n}{2}\left[1-3\left(\frac{a}{r}\right)^{4}+2\left(\frac{a}{r}\right)^{2}\right] \sin 2 \theta
\end{aligned}
$$

The above formulation does not include gravity forces (and thus there is no size effect) since gravity forces on the small drill holes proposed would be negligible.

Determining the stresses in the $x$ and $y$ directions by the following familiar equations:

$$
\begin{aligned}
\sigma_{x} & =\frac{\sigma_{\theta}+\sigma_{r}}{2}+\left(\frac{\sigma_{\theta}-{ }^{\sigma_{r}}}{2}\right) \cos 2 \theta+\tau_{r \theta} \sin 2 \theta \\
\sigma_{y} & =\frac{\sigma_{\theta}+{ }^{\sigma_{r}}}{2}-\left(\frac{\sigma_{\theta}-{ }^{\sigma_{r}}}{2}\right) \cos 2 \theta-T_{r \theta} \sin 2 \theta \\
\tau_{x y} & =-\left(\frac{\sigma_{\theta}-{ }^{\sigma_{r}}}{2}\right) \sin 2 \theta+\tau_{r \theta} \cos 2 \theta
\end{aligned}
$$

6 


\section{DEFINITION OF TERMS}

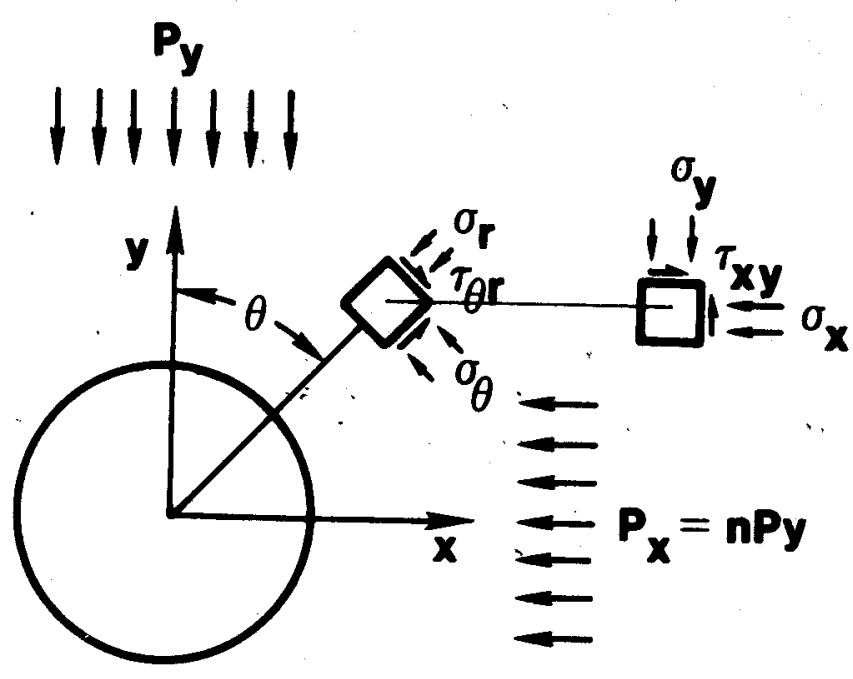

(a)

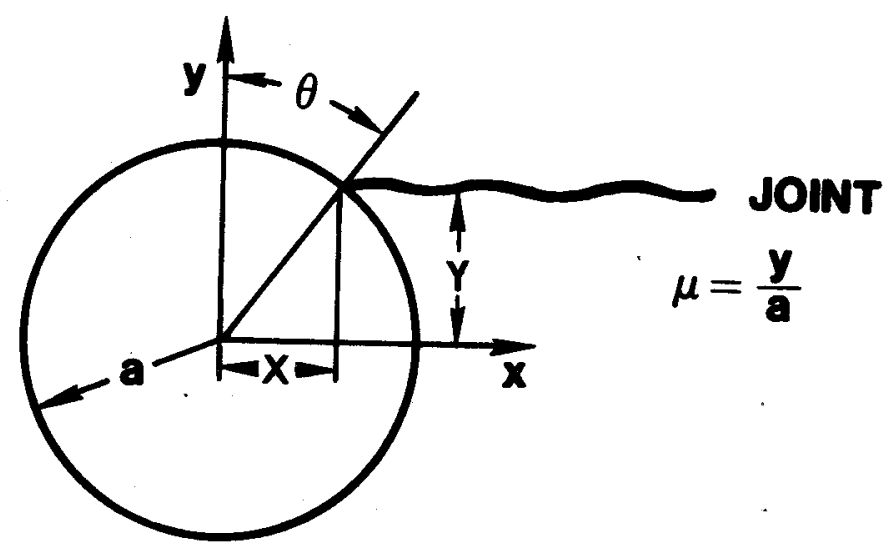

(b)

Figure 1. Definition of Terms: a) Cylindrical Drill Hole in Solid Mass Under Plane Strain, Isothermal, and Elastic

Conditions; b) Drill Hole - Fracture Configuration 
and expressing the results in normalized, Cartesian

coordinates, one obtains:

$$
\begin{aligned}
& \frac{\sigma y}{P_{y}}=\left[s-2 t \frac{\beta}{\alpha}\right]-\frac{\beta}{\alpha^{2}}\left[s-t \beta\left(1-\frac{2}{\alpha}+\frac{3}{\alpha}\right)\right]+4 t\left(\frac{\mu \lambda}{\alpha}\right)^{2}\left(1+\frac{2}{\alpha}-\frac{3}{\alpha^{2}}\right) \\
& { }_{\frac{T}{x}}^{P_{y}}=\frac{2 \mu \lambda}{\alpha^{2}}\left[2 t \frac{\beta}{\alpha}\left(\frac{3}{\alpha}-2\right)-s\right]
\end{aligned}
$$

where

$$
\begin{array}{ll}
\lambda=\frac{x}{a} & \beta=\mu^{2}-\lambda^{2} \\
\mu=\frac{y}{a} & s=\frac{1+n}{2} \\
a=\mu^{2}+\lambda^{2}=\frac{1}{a^{2}}\left(y^{2}+x^{2}\right) & t=\frac{1-n}{2}
\end{array}
$$

Equations (1) and (2) describe the stress field around a drill hole in a continuum. If it is assumed a joint does not induce stress changes, stresses along a hypothetical joint can be calculated. Figure 2 plots equation (1) for three horizontal-vertical stress ratios: $P_{x}=n P_{y}, n=0.5, n=1.0$, and $n=2.0$. The curves terminate at the point of intersection of the fracture with the drill hole. Both Figures $2 a$ and $2 b$ (horizontal stress less than or equal to the vertical stress) are similar in shape. In both cases the normal stress increases dramatically as the joint plane approaches the drill hole axis $(\mu=\gamma / \mathrm{a}=0.0)$.

When the horizontal stress is twice as large as the vertical stress $(n=2.0)$, the stress change due to the drill hole does not show a uniform progression. This phenomenon causes odd behavior in the permeability changes as seen in Figure 4 which is discussed later. (This stress condition 
STRESS CONCENTAATION NEAR DALL HOLE

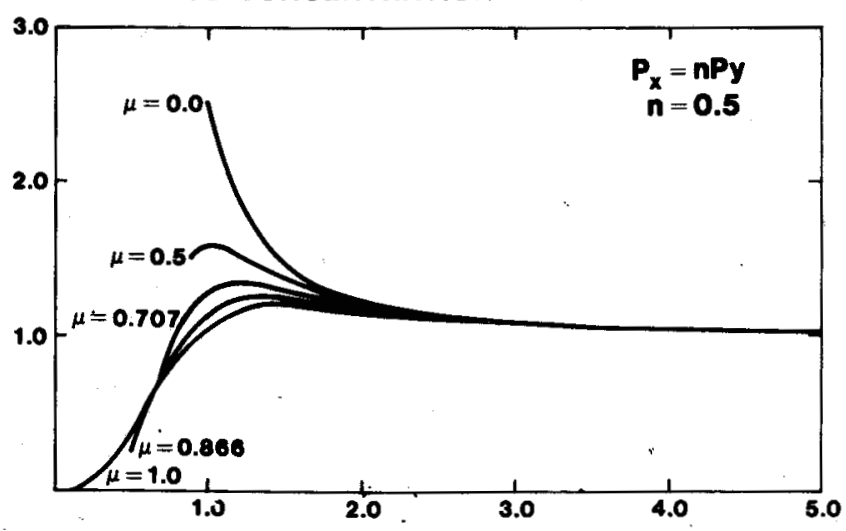

a)

b)
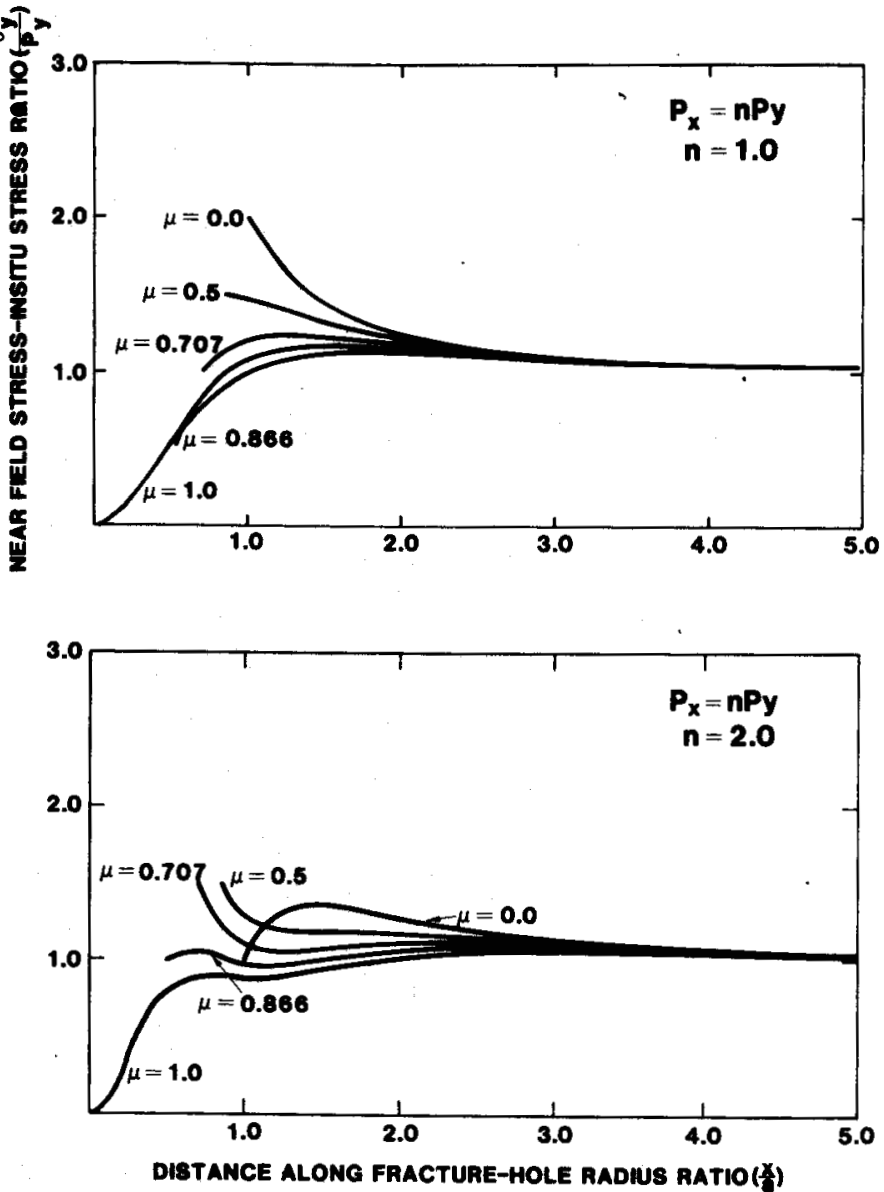

c)

Figure 2. Normal Stress Concentration Along a Joint for Three Horizontal-Vertical Stress Ratios., $P_{x}=n P_{y}$
a) $n=0.5$
b) $\mathrm{n}=1.0$
c) $n=2.0$. 
exists at several places where the nuclide migration experiment may be conducted.) It is evident, however, that the normal stress excursion decreases for all $\mu$ as $n$ increases in regions beyond the circle radius $(x / a>1)$.

The optimal drill hole position is that which minimizes stress changes. A tangential intersection of the drill hole clearly minimizes the joint normal stress changes for $n \leq 1$. As $n$ increased beyond 1.0 , the optimal position shifts to $\mu=0.866$. A tangential intersection only slightly relieves joint stresses. However, it is still nearly optimal.

For a tangential intersection, unusual stress behavior might occur in the small triangular region between $0<x / a<1$. It is likely the joint would open slightly. It is also possible for the triangular region to break out during drilling. However, it was assumed the joint did not introduce any change in the stress field. The validity of this continuum approach was verified by evaluating shear stresses along the joint and comparing with shear strength for possible slippage. Figure 3 plots the ratio of the shear stress and the near field, normal stress $\left(\tau_{x y} / \sigma_{y}\right)$ versus $x / a$. The relationship was obtained from equations (1) and (2).

Goodman (1976) states that generally the coefficient of friction ( $f=\tau / \sigma_{n}$ where $\tau=$ shear stress and $\sigma_{n}=$ normal stress) varies in the range of 0.4 to 0.8 and $c$ an dip as 10 as 0.2 for sheet minerals such as mica. Byerlee (1978) found that at intermediate normal stress $\left(1-150 \mathrm{ks} i\right.$ or $\left.5-100^{\circ} \mathrm{MPa}\right)$ the friction generated was independent of rock type and initial surface roughness and equal to about 0.85 . The latter friction coefficient value was plotted on figure 3.

It is seen that only a small segment of the joint is subjected to shear stresses great enough to cause sippage. No slippage is predicted for $x / a$ values greater than 1.06 . When the horizontal stress is equal to or less than the vertical stress no slippage is predicted beyond $x / a=0.82$. Thus it appears reasonable to model the rock mass as a continuum without a joint for points beyond the hole radius. 


\section{Permeability}

Fracture permeability $(k)$ is a function of confining pressure $\left(P_{c}\right)$, internal fluid pressure $\left(P_{f}\right)$, temperature, aperture (e) and surface roughness (Kranz, et al, 1979). Analytically, the fracture permeability is frequently related to the square of the aperture (e) from a paraliel plate model (Bear, 1972). (The aperture, in turn, is dependent on the loading due to present and past mechanical, thermal, and fluid stresses.)

$$
k=\frac{e^{2}}{12}
$$

or

$$
\text { Q/ } \Delta h \quad \text { a ke }=\frac{e^{3}}{12} \quad \text { (cubic law) }
$$

where

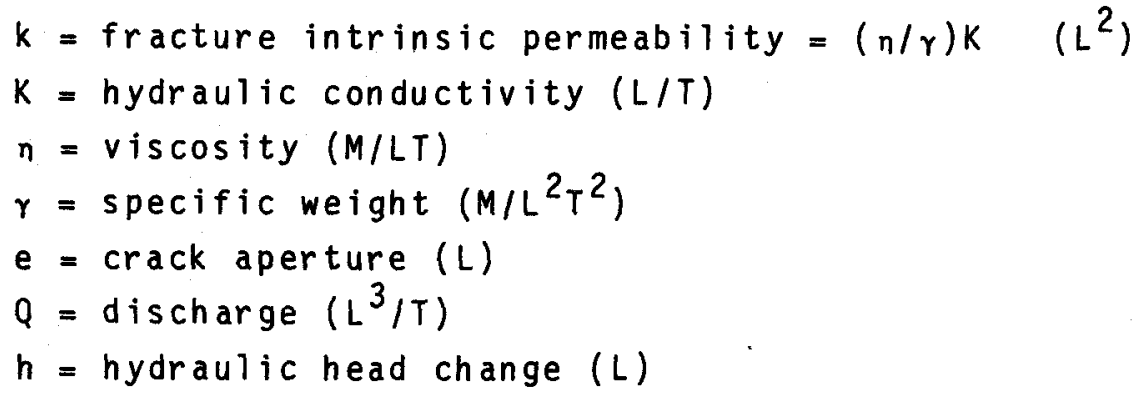

Witherspoon, et a1, (1980) found the cubic law to uniquely define permeability whether the fractures were held open or closed under stress. More importantly the results were independent of rock type, loading path, and load history.

It is readily apparent that while permeability might be uniquely determined by aperture, fracture dimensions cannot be determined in the field. Thus, the relationship of aperture or permeability versus applied stress must be known. Unfortunately, permeability and aperture do not appear to be unique functions of stress. Several experimenters (Kranz, et al, 1979; Iwai, 1976; Nelson and Handin, 1977) have found permanent alterations 
SHEAR stRESS ChANGE NEAR DRILL HOLE

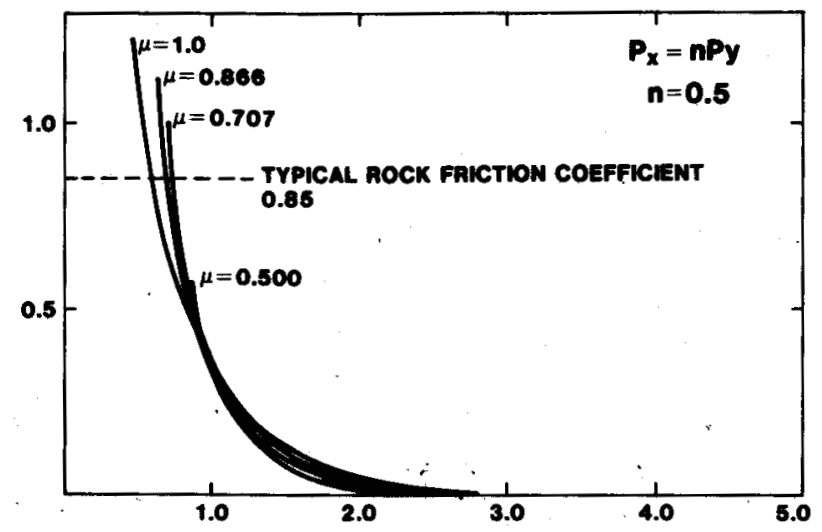

a)

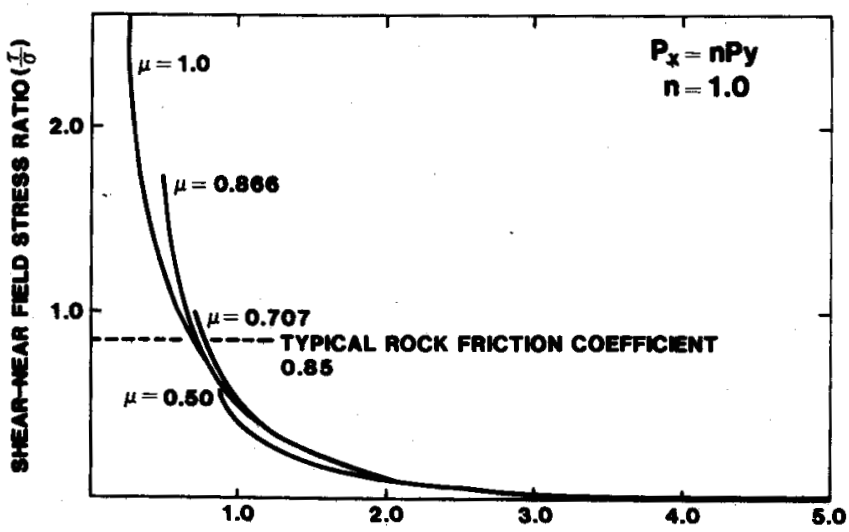

b)

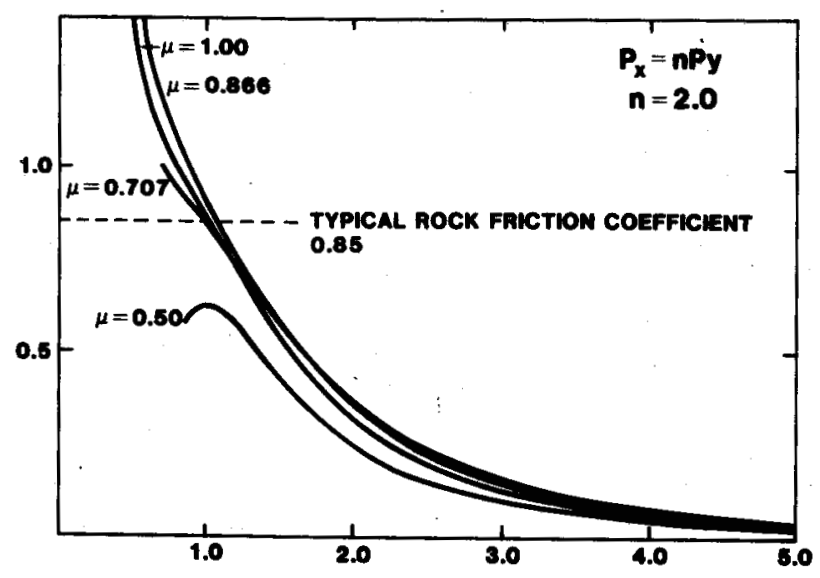

c)

Figure 3. Shear Stress Changes Along a Joint for Three Horizontal-Vertical Stress Ratios, $\mathrm{p}_{x}=n \mathrm{P}_{y}$
a) $\mathrm{n}=0.5$
b) $n=1.0$
c) $n=2.0$. 
(hysteresis) of permeability under cyclic loading. However, after 4 to 5 cyclic loadings at similar stress levels, repeatable permeability-stress curves were often produced (Iwai, 1976).

This observation is similar to the situation encountered in soil consolidation tests.

Gangi (1978) has published a power-law permeability-stress relationship using a bed-of-nails model as follows:

$$
\left(\frac{k e}{k e^{r}}\right)^{1 / 3}=1-\left(\frac{p}{E}\right)^{m}
$$

where

$$
k e^{\prime}=\text { zero pressure permeability-aperture product }\left(L^{3}\right)
$$

$E=$ effective modulus of asperities $\left(M / L T^{2}\right)$

$P_{f}=$ fluid pressure $\left(M / L T^{2}\right)$

$m=$ constant characterizing distribution function of asperity lengths, $0<m<1$ ( $m$ would supposedly change after each loading)

For this study, stress effects on the joint aperture were evaluated by using the preliminary results obtained by walsh (1981):

$$
\left(\frac{k e}{k_{0} e_{0}}\right)^{1 / 3}=\left(1-\frac{\sqrt{2 b}}{e_{0}}\right) \ln \left(\frac{p}{P_{0}}\right)_{e}
$$

where

$$
\begin{aligned}
& k_{0} e_{0}=\text { permeability-aperture product at reference state }\left(L^{3}\right) \\
& \left(P / P_{0}\right)_{e}=r a t i o \text { between unknown and reference effective pressures } \\
& b=r \cdot m . s \text {. of fracture surface protuberances (L) } \\
& \text { Equation (4) is similar in form to Jones' (1975) } \\
& \text { empirically derived formula: (ke) } 1 / 3=A-B \text { enp where } \\
& P_{C} \text { denotes the confining pressure. Both Walsh (1981) and } \\
& \text { Gangi (1978) have applied their equations to carbonate rock }
\end{aligned}
$$
data collected by Jones (1975) and found fairly good agreement. 
By assuming the validity of equation (3), it is possible to derive an expression for the aperture (e) using equation (4):

$$
e=e_{0}\left[1-\frac{\sqrt{2} b}{e_{0}} \ln \left(\frac{P}{P_{0}}\right) e\right]
$$

The parameter b would presumably account for hysteresis effects as stress was applied and taller asperites crushed.

From data found in Kranz, et al (1979) and Barre and Stesky (1980), Walsh back-calculated the term $\sqrt{2}$ b/e $e_{0}$ (from $k$ versus $\ln P$ data) and found it was approximately 1.4 for Barre granite and about 0.57 for pyroxene granulite. Data for Jones' coefficient $B$ (equivalent to $\sqrt{2}$ b/e $e_{0}$ in walsh formulation) is not available for volcanic tuff. For the calculations in this report, $B$ was assumed to be unity.

Permeability versus stress relationships for NTS tuff would be valuable experimental data to obtain for future work. Both laboratory and field data would be useful. No studies have been completed on the correspondence of $1 \mathrm{ab}$ and field fracture permeability coefficients. Consequently, the necessary lab specimen size to obtain representative field values is not known (Witherspoon, 1981).

The effects of changes in both confining pressure $\left(P_{C}\right)$ and the fluid pressure in the fracture $\left(P_{f}\right)$ are usually combined to give an effective pressure $\left(P_{e}\right)$. Traditionally $P_{e}$ is defined as $P_{C}{ }^{-P_{f}}$ in soil mechanics, but Walsh (1981) points out the relationship $P_{e}=P_{c}-S P_{f}$ may be a more appropriate effective stress 1 aw for fractured media. This relationship is supported by test results of $\mathrm{Kranz}$, et al (1978). The coefficient. S relates to the pore volume and the compressibility of the surrounding rock. Appropriate values of $S$ could be obtained from laboratory experiments relating $k$ versus $\ell n P_{c}$ for the material of interest. Because it was not possible to evaluate an effective pressure $\left(P_{e}\right)$ in the 
analys is, it was assumed $P_{c}$ could be used in place of $P_{e}$ as a rough approximation. The substitution implies an atmospheric fluid pore pressure.

From examination of the effective stress law and assuming $S<1$, it is obvious that when $P_{c}$ is much larger than $P_{f}$ there should be little difference between $P_{e}$ and $P_{c}$. The fact that Jones (1975) was successful in using confining pressure $\left(P_{C}\right)$ in fitting data suggests the subsitution is acceptable.

Postulated permeability-aperture product (ke) changes from the drill hole stress perturbance are plotted in Figure 4 for vertical-horizontal stress ratios $(n)$ of $0.5,1.0,2.0$. Examining the case where $n=1.0$, the tangential joint intersection $(\mu=1.0)$ on ly reduced the permeability-aperture product (ke) a maximum of 31.5 percent $(x / a=1.75)$. The value of ke decreased 63.5 percent at this distance for $\mu=0.0$. At the point of intersection with the drill hole, ke theoretically decreased 97.2 percent for $\mu=0.0$ which suggests permeability changes could be substantial.

It is evident a tangential joint intersection minimizes the permeability changes for $n \leq 1$. This result follows directly from the cubic law and the plane strain, elastic analysis. But as indicated earlier, unusual stress behavior or cracking might occur in the region $0<x / a<1$ for a tangential intersection. It is also possible the joint would open. However, the increase in joint width and consequent permeability increase would be preferred. Entrance velocities would be lower. The experiment would thus simulate seepage conditions more realistically. A tangential intersection slightly increases permeability for $n>1$ but similar arguments apply. Therefore, a tangential joint intersection is preferred in all cases. 


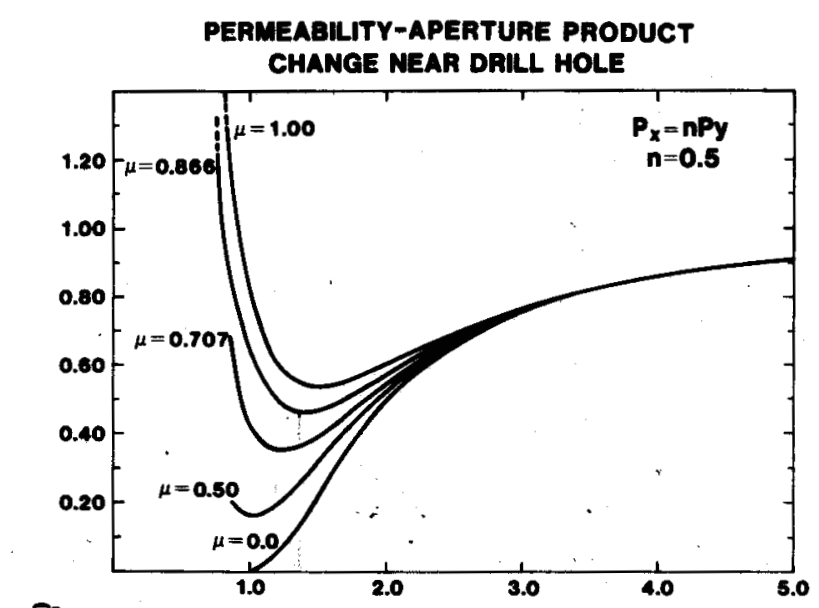

a)

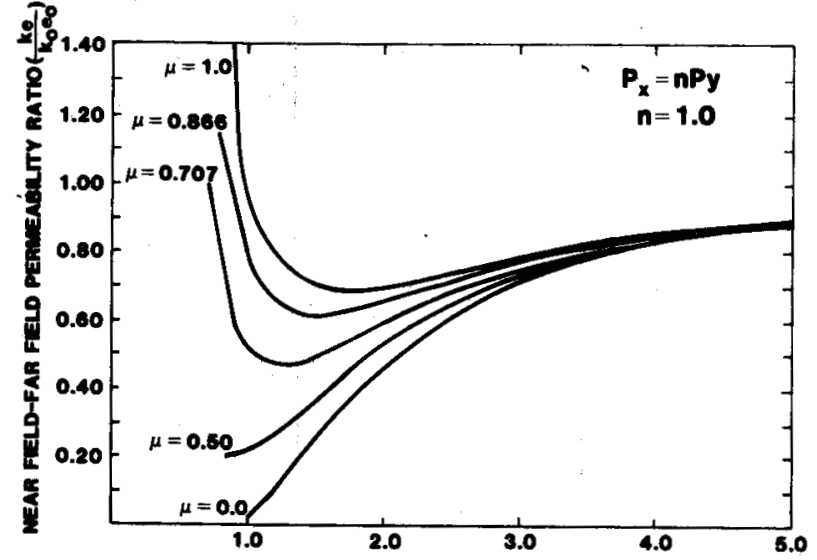

b)

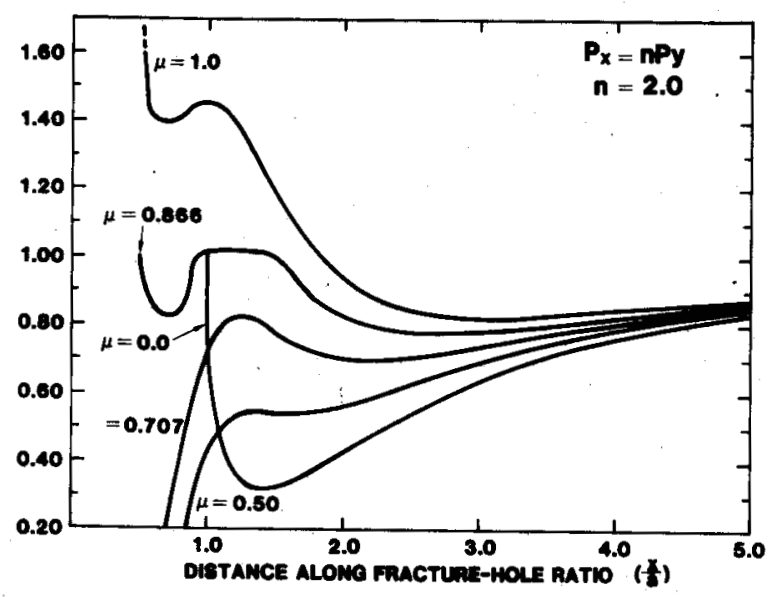

c)

Figure 4. Postulated Permeability Changes Using Cubic Logarithmic Law, $P_{x}=n P_{y} \quad$ a) $n=0.5 \quad$ b) $n=1.0 \quad$ c) $n=2.0$. 


\section{CONCLUSIONS AND RECOMMENDATIONS}

Based on the simplified analysis, a tangential intersection of the joint by the drill hole should be used to minimize disturbances of joint permeability in the field nuclide migration experiment. This assumes the instrumentation hole can be accurately placed along the joint.

The experiment will be difficult to perform and might benefit from a redesign to a perpendicular intersection of the joint by both the injection and collection holes. The radial flow experiment has two distinct advantages. First, the single fracture of interest does not have to be accurately traced. Brace (1978) and Witherspoon (1981) point out researchers have generally found large variations in individual joint behavior at distances greater than $1 \mathrm{~m}(3 \mathrm{ft})$. Second, the perpendicular intersection would eliminate normal stress concentrations along the joint. Laboratory experiments to date have avoided sheet-flow experiments (Iwai, 1976) in favor of the easily prepared and performed radial flow experiments.

A radial flow experiment can suffer from inherent hydraulic difficulties due to high inlet velocities with the potential to negate Darcy's law. Fortunately, velocities encountered at inlets for fractures are probably negligible (Iwai, 1976).

Although the perpendicular intersection would eliminate normal stress concentrations, small shear stresses could potentially develop during drilling. As a drill hole approached a joint, the rock mass above the joint would be free to relax while the lower portion would not. This situation would cause shear stresses along the joint. The shear stress could be diminished by drilling beyond the joint. Little data exist on the extent shear stress affects permeability. Conceivably dilatancy with a subsequent increase in permeabjlity occurs if 
the normal, in-situ stress is not large. Pratt, et al (1977) found that a $3 \mathrm{MPa}(0.44 \mathrm{ksi})$ stress applied normal to a fractured $3 \mathrm{~m}$ ( $6 \mathrm{ft}$ ) block of granite halved the original permeability. It was necessary to apply $12 \mathrm{MPa}(1.7 \mathrm{ksi})$ parallel to the joint to double the permeability. Thus, it can be tentatively assumed shear stress has less influence than normal stress on permeability. 


\section{REFERENCES}

1. Bear, Jacob, 1972, Bynamics of Fluids in Porous Media, Elsevier, New York.

2. Byerlee, J. D., 1978, "Friction of Rocks," Pure and Applied Geophysics (PAGEOPH), Vol. 116, No. 4.

3. Erdal, B. R., et. al., 1981, "Nuclide Migration Field Experiments - Program Plan, Report No. LA-8787-MS, Los A) amos Nationa 1 Laboratory.

4. Gangi, A. F., 1978, "Variation of Whole and Fractured Porous Permeability with Confining Pressure," Int. J. Rock Mech. Min. Sci. and Geomech. Abstr., Vol. 15, pp 249-257.

5. Goodman, R. E., 1980, Introduction to Rock Mechanics, John Wiley and Sons, New York.

6. Iwai, Katsuhiko, 1976, "Fundamental Studies of Fluid Flow Through a Single Fracture," Ph. D. Thesis, Civil Eng., University of California, Berkeley.

7. Jones, F. 0., 1975, "A Laboratory Study of the Effects of Confining Pressure on Fracture Flow and Storage Capacity in Carbonate Rocks, J. Petrol. Technol., Vol 21, pp 21-27.

8. Kranz, R. L., A. D. Frankel, T. Engelder, and C. H. Scholz, 1979, "The Permeability of Whole and Jointed Barre Granite," Int. J. Rock Mech. Min. Sci. and Geomech. Abstr., Vo1. 16, pp 225-234.

9. Nelson, R. A., and J. Handin, 1977, "Experimental Study of Fracture Permeability in Porous Rock," Amer. Assoc. of Pet. Geol. Bul1., Vol 61, No. 2., pp 227-236.

10. Walsh, J. B., 1981, "Effect of Pore Pressure and Confining Pressure on Rock Permeability," Seminar presented January 20, 1981 at Sandia National Laboratories.

11. Witherspoon, P. A., 1981, "Effect of Size on Fluid Movement in Rock Fractures," Geophysical Research Letters, Vol. 8, No. 7, pp 659-661.

12. Witherspoon, P. A., J. S. Y. Wang, K. Iwai, and J. E. Gale, 1980, "Validity of Cubic Law for Fluid Flow in a Deformable Rock Fracture," Water Resources Research, Vol. 16, No. 6, pp 1016-1024. 
Distribution:

TIC-4700-R69 UC-70/305

W. Ballard, Director

Office of Waste Isolation

U.S. Dept. of Energy

Room B-207

Germantown, MD 20767

R. Stein,'Acting Team-Leader

Technology Team

U.S. Dept. of Energy

Room B-220

Germantown, MD 20767

J. 0. Neff, Program Manager

National Waste Terminal Storage Program office

U.S. Dept. of Energy

$505 \mathrm{King}$ Avenue

Columbus, $\mathrm{OH} 43201$

L. D. Ramspott

Technical Project officer Lawrence Livermore Nat. Lab. University of California

P. 0 . Box 808

Mail Stop L-204

Livermore, CA 94550

A. R. Hak 1, Site Manager

Westinghouse - AESD

P. 0. Box 708

Mail Stop 703

Mercury, NV 89023

R. G. Gor anson

U.S. Dept. of Energy

Richland Operations office

P. 0 . Box 550

Richland, WA 99352

D. F. Miller, Director

Office of Public Affairs

U.S. Dept of Energy

P. 0. Box 14100

Las Vegas, NV 89114

B. W. Church, Director

Health Physics Division

P. 0. Box 14100

Las Vegas, NV 89114
G. L. Dixon

Technical Project Officer

U.S. Geological Survey

P. 0. Box 25046

Mail Stop 954

Federal Center

Denver, CO 80225

W. E. Wilson

U.S. Geological Survey

P. 0. Box 25046

Mail Stop 416

Denver, CO 80225

W. S. Twenhofel

820 Estes Street

Lakewood, CO 80215

B. R. Erdal

Tech. Project officer

Los Al amos Nat. Lab.

University of $\mathrm{C}$ alifornia

P. 0. Box 1663

Mail Stop 514

Los Alamos, NM 87545

C. R. Caoley

Deputy Director

U. S. Dept. of Energy

Room B-214

Germantown, MD 20767

R. Deju

Rockwell International

Atomics Intnl. Div.

Rockwe $11 \mathrm{H}$ anford Operations

Richland, WA 99352

R. M. Nelson, Director (3)

Waste Management Proj. Office

U.S. Dept. of Energy

P. 0. Box 14100

Las Vegas, NV 89114

R. H. Marks

U. S. Dept of Energy

$C P-1, M / S 210$

P. 0. Box 14100

Las Vegas, NV 89114 


\author{
R. R. Loux (7) \\ U.S. Dept. of Energy \\ P. O. Box 14100 \\ Las Vegas, NV 89114 \\ K. Street, Jr. \\ LLNL \\ Univ. of ,California \\ Mail Stop L-209 \\ P. 0. Box 808 \\ Livermore, CA 94550 \\ W. A. Carbiener \\ Battelle \\ Office of NWTS Integration \\ $505 \mathrm{King}$ Avenue \\ Columbus, $\mathrm{OH} 43201$ \\ S. Goldsmith \\ Battelle \\ Office of Nuc. Waste Isolation \\ 505 King Avenue \\ Columbus, $\mathrm{OH} 43201$
}

R. M. Hill

State Planning Coordinator

Governor's office of

Planning Coordination

Capitol Complex

Carson City, NV 89023

H. D. Cunningham

Reynolds Elec. Engr. Co. Inc. Mail Stop 555

P. 0. Box 14400

Las Vegas, NV 89114

J. A. Cross

Fenix Scisson, Inc.

P. 0. Box 15408

Las Vegas, NV 89114

A. J. Rothman (2)

LLNL, MS L-204

University of $C$ alifornia

P. 0. Box 808

Livermore, CA 94550
A. E. Gurrola

Holmes Narver, Inc.

P. 0. Box 14340

Las Vegas, NV 89114

D. C. Hoffman

LANL

Mail Stop 760

P. 0. Box 1663

Los Alamos, NM 87545

N. E. Carter

Battelle

Office of Nuc. Waste Is olation

$505 \mathrm{King}$ Avenue

Columbus, $\mathrm{OH} 43201$

ONW I Library (5)

Battelle

of. of Nuc. Waste Isolation 505 King Avenue

Columbus, $\mathrm{OH} 43201$

N. A. Clark

Dept. of Energy

State of Nevada

Capitol Complex

Carson City, NV 89710

J. P. Colton

International Atomic Energy Agency

Div. of Nuc. Power Reactors Wagarmerstrasse 5

P. 0. Box 100; A-1400

Vienna, Austria

A. M. Friedman

Argonne Nat. Laboratories

$9700 \mathrm{~S}$. Cass Avenue

Argonne, IL 60439 


$\begin{array}{ll}1417 & \text { F. W. Muller } \\ 4760 & \text { R. W. Lynch } \\ 4761 & \text { L. W. Scully } \\ 4762 & \text { L. D. Tyler } \\ 4763 & \text { J. R. Tillerson } \\ 4763 & \text { B. S. Langkopt } \\ 4763 & \text { A. R. Lappin } \\ 4763 & \text { R. M. Zimmerman } \\ 4763 & \text { R. Shaw } \\ 4764 & \text { R. C. Lincoln } \\ 4764 & \text { A. E. Stephenson } \\ 5500 & \text { O. E. Jones } \\ 5510 & \text { D. B. Hayes } \\ 5511 & \text { J. W. Nunziato } \\ 5511 & \text { D. K. Gartling } \\ 5520 & \text { T. B. Lane } \\ 5521 & \text { R. D. Krieg } \\ 5521 & \text { R. D. Thomas } \\ 5522 & \text { T. G. Priddy } \\ 5522 & \text { R. P. Rechard (5) } \\ 5522 & \text { K. W. Schuler (5) } \\ 5530 & \text { W. Herrmann } \\ 5531 & \text { M. L. Blanford } \\ 5532 & \text { B. M. Butcher } \\ 5532 & \text { W. A. Olsson } \\ 5541 & \text { W. C. Luth } \\ 8266 & \text { E. A. Aas } \\ 3141 & \text { L. J. Erickson } \\ 3151 & \text { W. L. Garner } \\ & \text { For: DoElTIC (Un limited Release) (3) } \\ 3154-3 & \text { C. H. Dalin } \\ & \text { For DoE/TIC (25) } \\ & \end{array}$

